\title{
Controlled Release Fertilizer Encapsulated by Glutaraldehyde-Crosslinked Chitosan Using Freeze-Drying Method
}

\author{
Adhitasari Suratman*, Dwi Ratih Purwaningsih, Eko Sri Kunarti, and Agus Kuncaka \\ Department of Chemistry, Faculty of Mathematics and Natural Sciences, Universitas Gadjah Mada, \\ Sekip Utara, Yogyakarta 55281, Indonesia
}

* Corresponding author:

email: adhitasari@ugm.ac.id

Received: March 30, 2020

Accepted: May 28, 2020

DOI: $10.22146 /$ ijc.55133

\begin{abstract}
A new encapsulation of NPK fertilizer hydrogel granules made from glutaraldehyde crosslinked chitosan has been successfully fabricated. This designed fertilizer was aimed to maximize the fertilizing process in the soil, as the environmental pollution affected by the excess release of the nutrients can be prevented. The granule was prepared from biodegradable chitosan crosslinked with glutaraldehyde by applying a method of air and freeze-drying. The release test proved that this designed fertilizer showed a good performance as a Controlled Release Fertilizer (CRF) in which the hydrogel granules could absorb and deposit large amounts of NPK. Later on, they could also release large amounts of NPK as well, unlike several types of CRFs. The release percentage of NPK out of the granules tended to decrease with an increase of $\mathrm{pH}$ at a range close to the average $\mathrm{pH}$ of the soil, which is neutral to base. Comparing two methods, the freeze-drying technique, which yields a bigger pore size, showed a higher release percentage than airdrying. The release kinetics of the granules followed the Korsmeyer-Peppas model.
\end{abstract}

Keywords: hydrogel; controlled release fertilizer; freeze-drying; chitosan; glutaraldehyde

\section{- INTRODUCTION}

Fertilizers are very important in agriculture, where it is needed by soil to afford essential nutrients required by the plants [1]. However, the fertilizer losses in the soil are still one of the main concerns in the use of fertilizers [2]. Around $40-70 \%$ of nitrogen, $80-90 \%$ phosphorus, and $50-70 \%$ potassium from fertilizers are wasted to the environment without any absorption of the root plant. This problem causes not only economic and resource loss but also causes environmental pollution [3]. Therefore, efficient nutrient absorption from fertilizers to the plants should be increased to avoid nutrient loss during the process in the soil media by controlling the processes in fertilizers, soil media, and plant absorption. In this study, the fertilizer released to the soil media will be observed by controlling the amount of substances such as $\mathrm{N}, \mathrm{P}, \mathrm{K}$, where adjustment of the release rate of the controlled release fertilizer (CRF) method is used. The granules that are composed of fertilizer and crosslinked chitosan are modified to adjust certain release mechanisms and to regulate the release rate based on the physical characterization of the granules, such as diffusion, swelling, polymer matrix degradation that affects the release pattern of the fertilizer [4-6]. A hydrogel is a type of matrix that is known and used to control the release of fertilizers into the soil [7]. A hydrogel is a 3Dnetworking hydrophilic polymer that is capable of keeping water in their structure and is dissoluble in water [8-11], therefore it is a good material to be used as a fertilizer media. In addition, the use of hydrogels for fertilizer release can increase efficiency, reduce soil toxicity, and minimalize the potential loss of nutrition, and improve the soil quality [12].

Chitosan, which is a natural polysaccharides obtained from the deacetylation of chitin and formed from $\beta$-(1-4)-2-amino-deoxy- $\beta$-D-glucose [13], does not dissolve in water, organic solvents, alkaline solutions, and mineral acids at $\mathrm{pH}$ above 6.5 [14], and is classified as biodegradable and non-toxic [15], a cationic polymer, and it can form a complex structure with anionic polymers or cross-linking agents [16], such as glutaraldehyde [17]. The solubility of chitosan is affected by the protonation 
of the amino groups in the polymer chains [18], and by the crosslinkage with glutaraldehyde that increases the structure stability in acidic solution [19]. Chitosan, a natural and inexpensive source of material found in shrimp and crab, was used in this study as a porous-structure media to keep the NPK fertilizer. Freeze-drying used for the hydrogel formation is based on a dry process in which the solvent media (water) will crystallize at low temperatures and sublimate to the vapor phase [20] in the vacuum [21] and sublimation condition [22]. The shape of pores, pore size distribution, and pore connectivity of the matrix will be formed by ice sublimation during the processes [23]. The benefits of using freeze-drying are long-term-storage use, damage reduction from heat, prevent microorganism activity and excessive stress, and also avoid change of the sample appearance $[21,24]$. The preparation of porous hydrogels from chitosan using the freeze-drying technique for controlled release fertilizers has not been reported until now. The crosslinking process in chitosan is to afford adequate pores of hydrogel to store and release the NPK fertilizer at different conditions of $\mathrm{pH}$ in the soil.

\section{- EXPERIMENTAL SECTION}

\section{Materials}

The materials used in this study were chitosan, glacial acetic acid, potassium dihydrogen phosphate, potassium solution $1000 \mathrm{mg} / \mathrm{L}$, ammonium molybdate, ammonium vanadate, glutaraldehyde, potassium hydroxide, citric acid $65 \%$, hydrochloric acid $37 \%$ from E.

Merck, Germany. NPK fertilizer and deionized water were obtained from a local market.

\section{Instrumentation}

Instruments used in this study were Fourier Transform Infrared (FTIR) Spectrometer from Shimadzu Prestige 21, Scanning Electron Microscopy (SEM) from Hitachi SU 3500, UV-Vis spectrophotometer from Thermo Spectronic 20D+, and Atomic Absorption Spectrophotometer (AAS) from Perkin Elmer 3110, and Freeze-dryer from LyoQuest Telstar.

\section{Procedure}

\section{Preparation of chitosan hydrogel}

The hydrogel was prepared by dissolving chitosan in
$10 \mathrm{~mL}$ acetic acid solution $0.1 \mathrm{M}(2 \% \mathrm{v} / \mathrm{v})$. One and a half grams of NPK fertilizer was then added into the solution under constant stirring for about $30 \mathrm{~min}$, followed with the addition of $0.16 \mathrm{~mL}$ glutaraldehyde solution $25 \%$ $(0.4 \% \mathrm{v} / \mathrm{v})$. The hydrogel was dried using the air-drying and freeze-drying method. Hydrogel yielded from freeze-drying was characterized using FTIR and SEM.

\section{The release mechanism of $N, P, K$}

The hydrogel of chitosan crosslinked with glutaraldehyde $(1.8 \mathrm{~g})$ was immersed into $20 \mathrm{~mL}$ of deionized water for 8 days. The aliquot solution of hydrogel was then filtered. The released amount of nitrogen out of hydrogel was determined with the Kjeldahl method [25]. The released amount of phosphor was determined by UV-Vis Spectrophotometer (at wavelength $426 \mathrm{~nm}$ ). Aliquot solution of about $0.125 \mathrm{~mL}$ was diluted 20 times in water, and about $2.5 \mathrm{~mL}$ was taken, added by $5 \mathrm{~mL}$ of a complexing solution of vanadomolybdate acid and water until the volume reaches $100 \mathrm{~mL}$. The calibration curve standard was made by absorbance measurement of phosphor standard solution with a concentration of $0.5-2.5 \mathrm{mg} / \mathrm{L}$ (interval $0.5 \mathrm{mg} / \mathrm{L}$ ). Potassium release was determined by diluting aliquot solution up to 8000 times, followed by measurement with Atomic Absorption Spectroscopy (AAS). The calibration curve standard was made by absorbance measurements of potassium standard solution from 1-5 mg/L (interval $0.5 \mathrm{mg} / \mathrm{L}$ ).

The release mechanism of nitrogen, phosphor, and potassium was determined using zeroth order, the first order, Higuchi and Korsmeyer-Peppas kinetics models (Table 1), where $C_{t}$ is NPK concentration at the time of $\mathrm{t}, \mathrm{C}_{0}$ is the initial NPK concentration in the hydrogel, $\mathrm{Q}$ is the release percentage, $M_{t}$ and $M \infty$ are amounts of

Table 1. Kinetics model equations for determination of release mechanism of $\mathrm{N}, \mathrm{P}$, and $\mathrm{K}$

\begin{tabular}{ll}
\hline Kinetics Model & Equation \\
\hline Zeroth order & $\mathrm{C}_{\mathrm{t}}-\mathrm{C}_{0}=-\mathrm{kt}$ \\
First order & $\ln [\mathrm{C}]=\ln [\mathrm{C}]_{0}+\mathrm{kt}$ \\
Higuchi & $\mathrm{Q}=\mathrm{k} \sqrt{\mathrm{t}}$ \\
Korsmeyer-Peppas & $\frac{\mathrm{Mt}}{\mathrm{M} \infty}=\mathrm{kt}^{\mathrm{n}}$ \\
\hline
\end{tabular}


nutrient released at a time $(\mathrm{t})$ and at equilibrium, $\mathrm{k}$ is a constant of the fertilizer-polymer system, and $\mathrm{n}$ is the diffusion exponent characteristic of the release mechanism in which for Quasi-Fickian diffusion is $\mathrm{n}=$ 0.5 ; non-Fickian or anomalous transport $\mathrm{n}=0.5-1.0$ and case II transport $\mathrm{n}=1.0$ [26-27]. The calculation result was used to determine the release of N, P, and $\mathrm{K}$ with NPK concentration variation.

\section{Swelling ratio of hydrogel at $\mathrm{pH}$ variation}

The hydrogel was immersed into $20 \mathrm{~mL}$ of solution at $\mathrm{pH} 1 ; 3 ; 5 ; 7 ; 9$ for $120 \mathrm{~min}$. The hydrogel was lifted and weighed every $10 \mathrm{~min}$ of immersion. The swelling percentage was calculated using the equation:

$\mathrm{SR}=\frac{\mathrm{Wx}-\mathrm{Wd}}{\mathrm{Wd}} \times 100 \%$

where $\mathrm{Wx}$ and $\mathrm{Wd}$ refer to the weight of the swollen hydrogel and dried hydrogel, respectively.

\section{NPK release at $p H$ variation}

The hydrogel was immersed into $20 \mathrm{~mL}$ of solution at $\mathrm{pH} 1$ for 8 days. The aliquot solution was filtered, and NPK content was determined by the Kjeldahl method and measured by UV-Vis spectrophotometer, and AAS. The same procedure was also done at $\mathrm{pH} 3 ; 5$; and 9.

\section{Air-drying method}

Hydrogel made by air-drying was obtained by heating at $70{ }^{\circ} \mathrm{C}$ for $24 \mathrm{~h}$ in the oven. The hydrogel product was immersed into $20 \mathrm{~mL}$ of deionized water for
8 days. The aliquot solution of the immersion was then filtered. The determination of NPK was done with the Kjeldahl method, UV-Vis spectrophotometer, and AAS. The performance of the resulting hydrogel using this method was compared with the freeze-drying method.

\section{- RESULTS AND DISCUSSION}

\section{Physical Characterization of the Glutaraldehyde Crosslinked Chitosan Hydrogel}

Hydrogel made by the freeze-drying method is expected to have high stability structures. FTIR data of the hydrogel was used to find material groups to comply with the hydrogel. The spectra is shown in Fig. 1.

FTIR data showed that -OH stretching of the hydrogel product was seen at about 3390 to $3500 \mathrm{~cm}^{-1}$ overlapping with $\mathrm{N}-\mathrm{H}$ stretching $\left(3132 \mathrm{~cm}^{-1}\right)$. The peak at wavenumber of around 1080 and at $1635 \mathrm{~cm}^{-1}$ were attributed to the vibrations of -C-O-C glycosidic linkage and $\mathrm{N}-\mathrm{H}$ bending, respectively. Interaction of the chitosan backbone with glutaraldehyde was indicated by the shifting of $\mathrm{N}-\mathrm{H}$ bending of uncrosslinked chitosan hydrogel to a lower wavenumber, at 1651 to $1635 \mathrm{~cm}^{-1}$. This wavenumber shifting of a similar crosslinking process was also reported by Akakuru and Isiuku [28].

The SEM images of hydrogel prepared by airdrying and freeze-drying are shown in Fig. 2. It is shown that both hydrogels have clear differences on their surface. The massive surface was seen on the air-drying

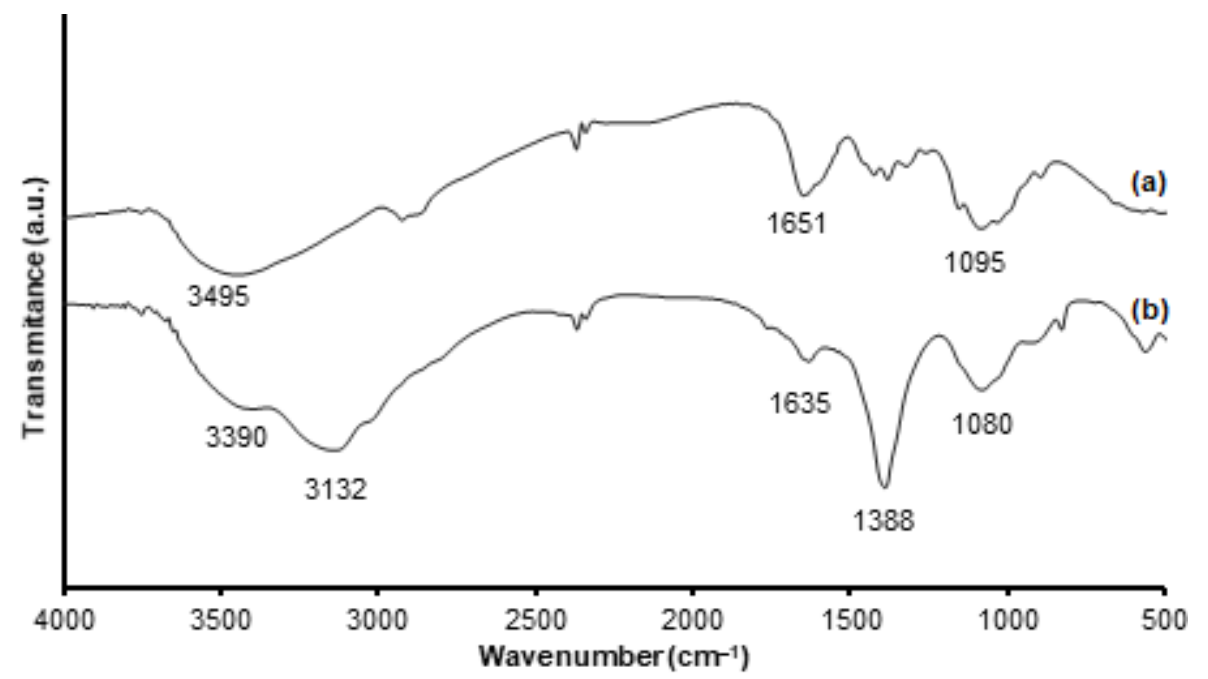

Fig 1. Spectra of (a) chitosan and (b) chitosan crosslinked glutaraldehyde hydrogel 

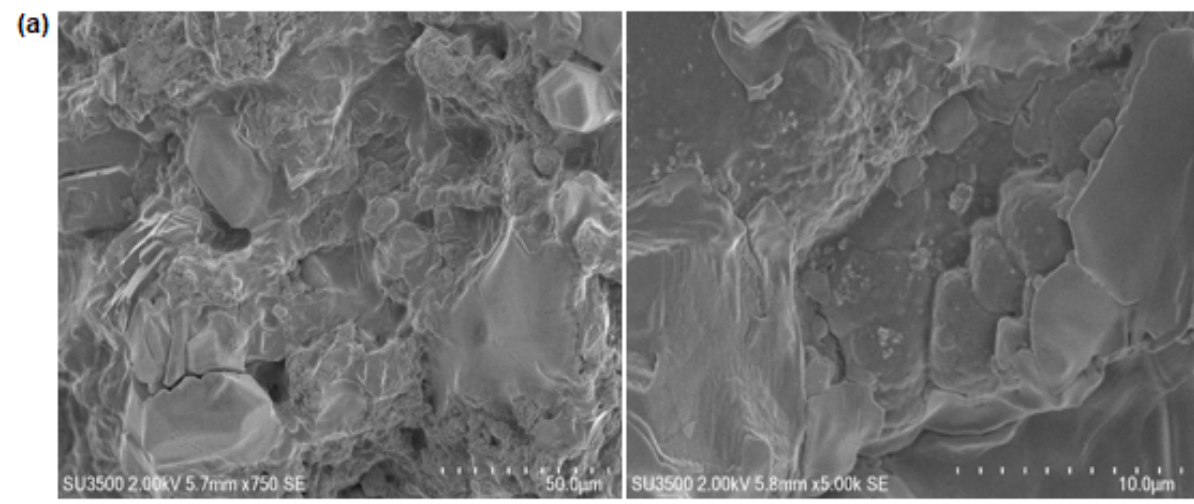

(b)

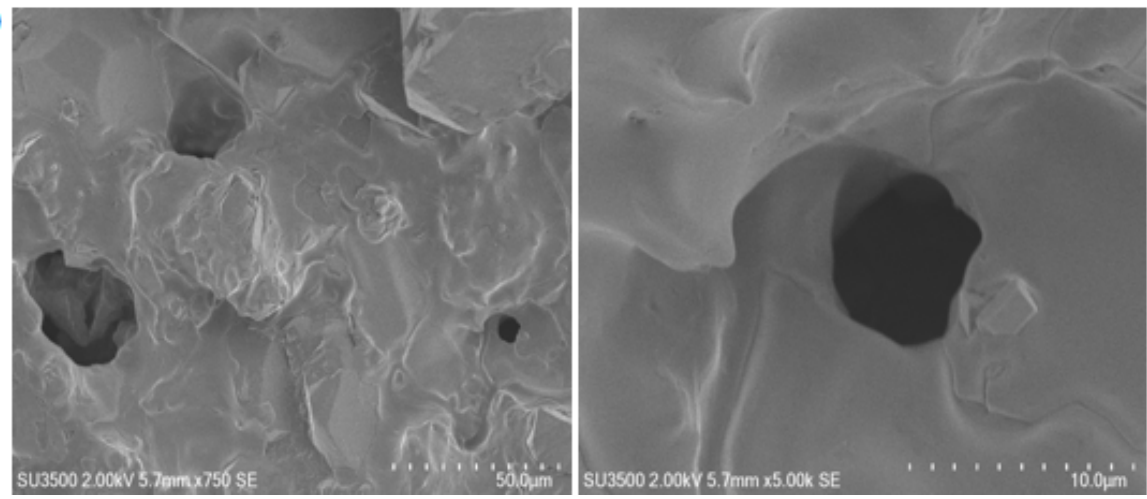

Fig 2. The surface morphology of chitosan hydrogel made with (a) air-drying, and (b) freeze-drying

hydrogel (Fig. 2(a)). The surface with pores was clearly seen on the surface of the hydrogel made by freeze-drying (Fig. 2(b)). The pores on the hydrogel structure was advantageous for the solvent absorption and swelling structure change of the hydrogel.

\section{The Release Kinetics Model of Nitrogen, Phosphor, and Potassium}

The release of $\mathrm{N}, \mathrm{P}$, and $\mathrm{K}$ was studied using fertilizer concentration of $1.5 \mathrm{~g}$ that was immersed in deionized water for 8 days. The results are shown in Fig. 3.

From Fig. 3, we can see that the release of N, P, and $K$ from the hydrogel significantly increased until the $5^{\text {th }}$ day and became constant in the following days. The release mechanism of $\mathrm{N}, \mathrm{P}$, and $\mathrm{K}$ was investigated using zeroth order, first order, Higuchi, and Korsmeyer-Peppas kinetics model. The correlation coefficient $\left(\mathrm{R}^{2}\right)$ is shown in Table 2.
Table 2 shows that the release of $\mathrm{N}, \mathrm{P}$, and $\mathrm{K}$ from the glutaraldehyde crosslinked chitosan hydrogel followed the Korsmeyer-Peppas model, indicated by the regression value, which is close to 1 (0.99). The Korsmeyer-Peppas model explains that the release of N, $\mathrm{P}$, and $\mathrm{K}$ is due to the swelling of the hydrogel. The

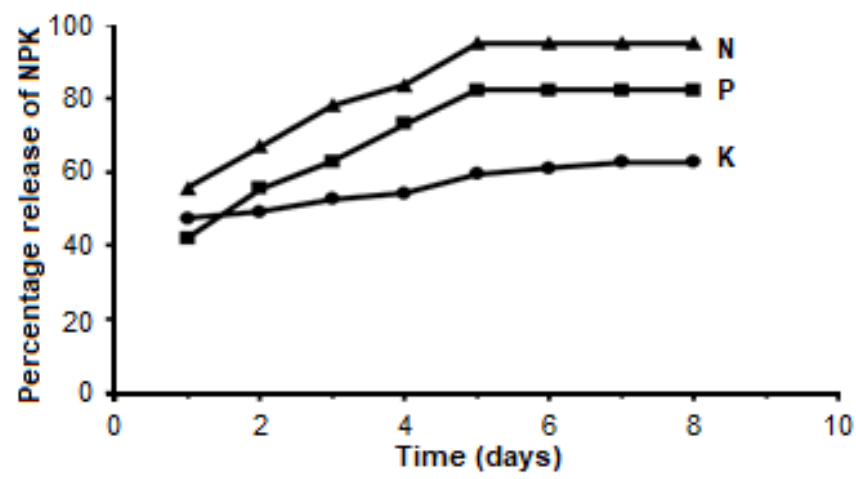

Fig 3. The release of $N, P$, and $K$ in water until 8 days

Table 2. Correlation coefficient $\left(\mathrm{R}^{2}\right)$ of the release kinetics of $\mathrm{N}, \mathrm{P}$, and $\mathrm{K}$

\begin{tabular}{lcccc}
\hline Nutrient & Zeroth order & First order & Higuchi & Korsmeyer-Peppas \\
\hline $\mathrm{N}$ & 0.94 & 0.96 & 0.46 & 0.99 \\
$\mathrm{P}$ & 0.98 & 0.98 & 0.97 & 0.99 \\
$\mathrm{~K}$ & 0.97 & 0.97 & 0.98 & 0.99 \\
\hline
\end{tabular}


calculation of the NPK release exponent (n), correlation coefficient $\left(\mathrm{R}^{2}\right)$, and release factor $(\mathrm{k})$ of the hydrogel are shown in Table 3.

From Table 3, we can see that the value of $\mathrm{n}$ from $\mathrm{N}$, $\mathrm{P}$, and $\mathrm{K}$ was smaller than 0.5 , indicating that the NPK release followed the Quasi-Fickian diffusion mechanism. It means that the release of NPK from the hydrogel was determined by partial diffusion of swelling and waterfilled pores of the hydrogel. The formation of the crosslinked chitosan with glutaraldehyde increased the swellability of the hydrogel because of the increase of density of the hydrogel when compared to the uncrosslinked hydrogel [28].

\section{Effect of Fertilizer Concentration on the Hydrogel}

The release of $\mathrm{N}, \mathrm{P}$, and $\mathrm{K}$ from the freeze-dried hydrogels were performed with fertilizer weight variation of $1 ; 1.5$; and $2 \mathrm{~g}$. This variation is aimed to investigate the effect of NPK fertilizer concentration on the kinetics of N, $\mathrm{P}$, and $\mathrm{K}$ releases. The data on the release of $\mathrm{N}, \mathrm{P}$, and $\mathrm{K}$ are shown in Fig. 4.

Fig. 4 shows that the increase of $\mathrm{N}, \mathrm{P}$, and $\mathrm{K}$ concentrations in the hydrogel caused the increase of $\mathrm{N}$, $\mathrm{P}$, and $\mathrm{K}$ releases. The release mechanism of $\mathrm{N}, \mathrm{P}$, and $\mathrm{K}$ was investigated using the kinetics model of Korsmeyer-
Peppas. The data of the release exponent (n), correlation coefficient $\left(\mathrm{R}^{2}\right)$, and release factor $(\mathrm{k})$ with the variation of $\mathrm{N}, \mathrm{P}$, and $\mathrm{K}$ concentrations are shown in Table 4 .

Table 4 shows that the release constants for nitrogen were $34.1 ; 49.2 ; 54.5 \mathrm{ppm} /$ day, for fertilizer concentrations of $1,1.5$, and $2 \mathrm{~g}$, respectively. For the same fertilizer concentrations, the release constants for phosphorus were $50.2 ; 54.7$; and $58.2 \mathrm{ppm} /$ day, while the release constants for potassium were $42.1 ; 42.2$; and $50.8 \mathrm{ppm} /$ day.

The data indicates that the reaction rate constant of nitrogen, phosphorus, and potassium increased with the increase of the NPK amount in the hydrogel. This shows that the concentration of the NPK fertilizer in the hydrogel affects the release of nitrogen, phosphorus, and potassium. Meanwhile, the $\mathrm{n}$ value of nitrogen, phosphorus, and potassium were smaller than 0.5 , indicating that the release of phosphorus and potassium followed the Quasi-Fickian diffusion mechanism [5].

\section{Swelling Ratio of the Hydrogel}

The swelling ratio of the hydrogel was studied by immersing the hydrogel in water at $\mathrm{pH}$ of $1 ; 3 ; 5 ; 7$; and 9 for $120 \mathrm{~min}$ (with $10 \mathrm{~min}$ interval). Fig. 5 shows the result for the investigation of the swelling of the hydrogel

Table 3. NPK release exponent (n), correlation coefficient $\left(R^{2}\right)$, and release factor $(k)$ of hydrogel

\begin{tabular}{lccc}
\hline \multirow{2}{*}{ Nutrient } & \multirow{2}{*}{ Correlation coefficient $\left(\mathrm{R}^{2}\right)$} & \multicolumn{2}{c}{ Korsmeyer-Peppas } \\
\cline { 3 - 4 } & & $\mathrm{n}$ & $\mathrm{k}(\mathrm{ppm} /$ day $)$ \\
\hline $\mathrm{N}$ & 0.99 & 0.13 & 49.3 \\
$\mathrm{P}$ & 0.99 & 0.27 & 60.9 \\
$\mathrm{~K}$ & 0.99 & 0.37 & 42.2 \\
\hline
\end{tabular}
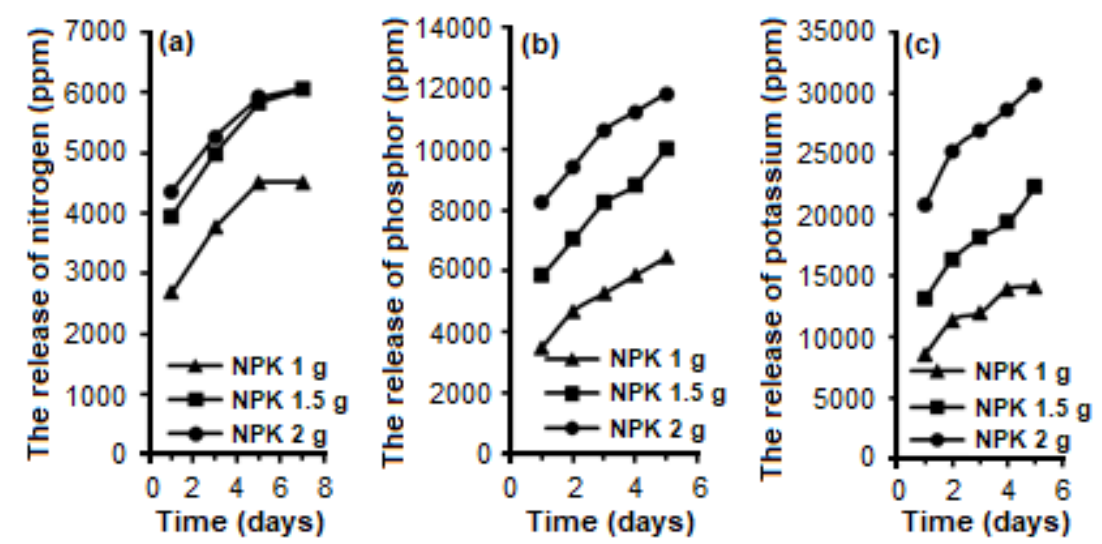

Fig 4. The release of (a) nitrogen, (b) phosphorus, and (c) potassium with fertilizer concentration variation 
Table 4. N, $P$, and $K$ release exponent $(n)$, correlation coefficient $\left(R^{2}\right)$, and release factor $(k)$ with the variation of fertilizer concentration

\begin{tabular}{lcccc}
\hline \multirow{2}{*}{ Nutrient } & $\begin{array}{c}\text { Concentration } \\
\text { of fertilizer }\end{array}$ & $\begin{array}{c}\text { Correlation } \\
\text { coefficient }\left(\mathrm{R}^{2}\right)\end{array}$ & \multicolumn{2}{c}{ Korsmeyer-Peppas } \\
\hline \multirow{2}{*}{$\mathrm{N}$} & $1.0 \mathrm{~g}$ & 0.97 & 0.28 & $\mathrm{k}(\mathrm{ppm} /$ day $)$ \\
\hline & $1.5 \mathrm{~g}$ & 0.99 & 0.23 & 49.2 \\
$\mathrm{P}$ & $2.0 \mathrm{~g}$ & 0.99 & 0.18 & 54.5 \\
\hline & $1.0 \mathrm{~g}$ & 0.99 & 0.37 & 50.2 \\
& $1.5 \mathrm{~g}$ & 0.98 & 0.32 & 54.7 \\
$\mathrm{~K}$ & $2.0 \mathrm{~g}$ & 0.99 & 0.22 & 58.2 \\
\hline & $1.0 \mathrm{~g}$ & 0.97 & 0.31 & 42.1 \\
& $1.5 \mathrm{~g}$ & 0.98 & 0.31 & 42.2 \\
& $2.0 \mathrm{~g}$ & 0.99 & 0.23 & 50.8 \\
\hline
\end{tabular}

due to water absorption into the pores of the hydrogel at $\mathrm{pH}$ variation. In general, the swellability of the hydrogel is influenced by the presence of hydroxyl groups $(-\mathrm{OH})$ that enhance the hydrophilicity and the presence of amino groups $\left(-\mathrm{NH}_{2}\right)$ that are protonated in water, mostly in acidic solution. Fig. 5 shows that the lowest swelling of the hydrogel occurred at $\mathrm{pH}$ 9. This was due to the $-\mathrm{NH}_{2}$ group of chitosan that was protonated to $-\mathrm{NH}_{3}{ }^{+}$. This protonation causes chain repulsion and diffusion in the base solution, $-\mathrm{NH}_{2}$ was not protonated.

\section{The NPK Release at Variation of pH Solution}

The NPK release of the hydrogel at $\mathrm{pH} 1 ; 3 ; 5$; and 9 for 5 days are shown in Fig. 6.

From Fig. 6, it is shown that the lowest NPK release occurred at $\mathrm{pH} 9$, NPK release in the acidic solutions were higher because the acidic $\mathrm{pH}$ causes the unreacted $-\mathrm{NH}_{2}$ group to be protonated. The protonation increase the swelling of the hydrogel, causing the solvent to easily enter the pores of the hydrogel resulting in higher NPK release.

\section{The Effect of Drying Method}

The effect of the freeze-drying and air-drying methods are shown in Fig. 7.

Fig. 7 shows that the release of N, P, and $\mathrm{K}$ from the freeze-dried hydrogels was relatively higher than the

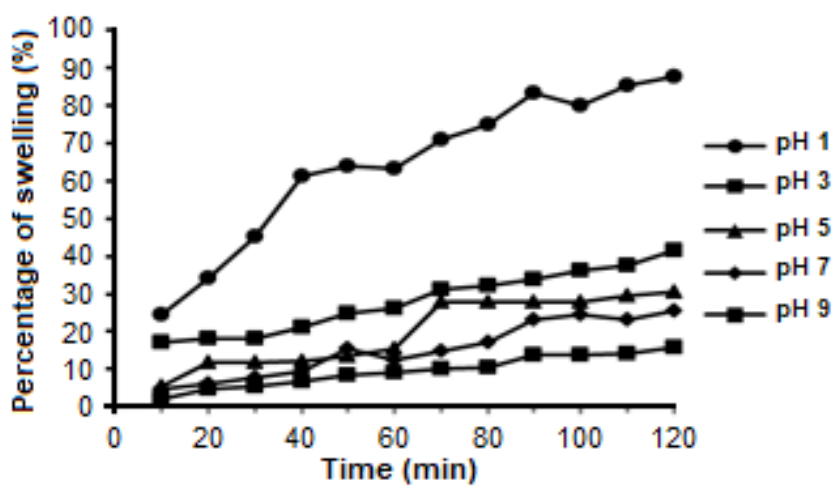

Fig 5. The swelling ratio of hydrogel at $\mathrm{pH}$ variation
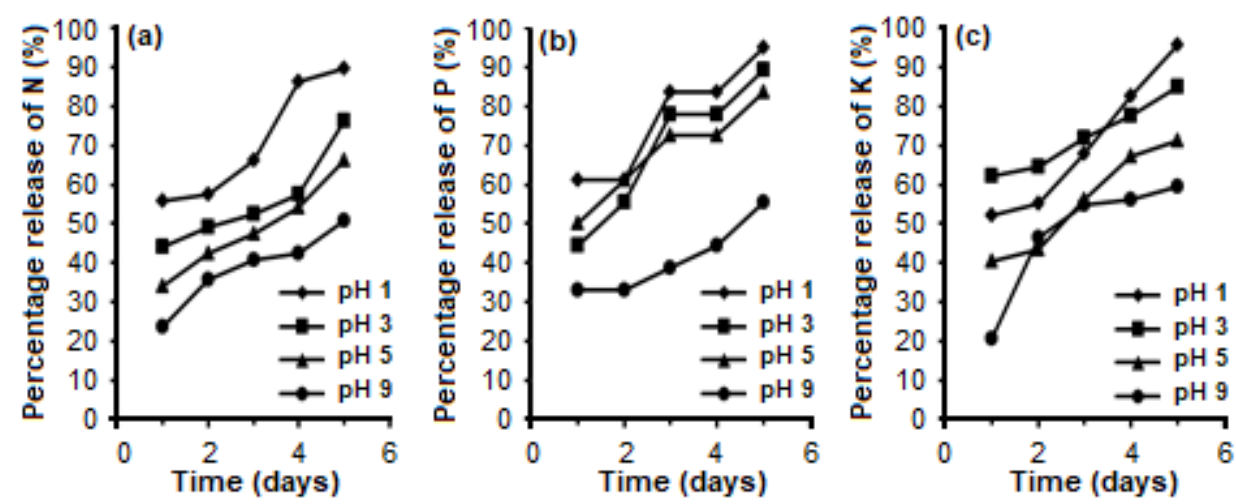

Fig 6. The release of (a) nitrogen, (b) phosphor, (c) potassium at $\mathrm{pH} 1 ; 3 ; 5 ; 9$ 

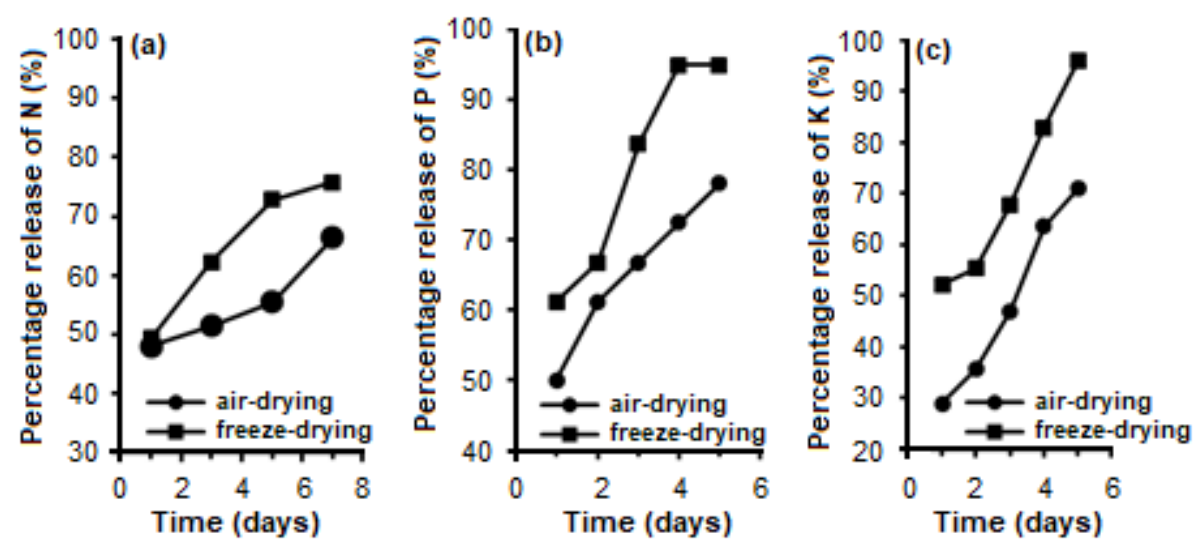

Fig 7. The release (a) nitrogen, (b) phosphor, (c) potassium by freeze, and air-drying method

air-dried hydrogels. It was clear that the pore formation in the freeze-drying method caused the absorption of the solvent leading to higher swelling ratio and caused the diffusion process to be more efficient.

\section{- CONCLUSION}

The NPK release rate increased with the increase of NPK fertilizer concentration that were deposited in the hydrogel structure. The release of NPK from the hydrogel followed the Korsmeyer-Peppas model. The swelling ratio of the hydrogel at acidic $\mathrm{pH}$ was higher than at $\mathrm{pH} 9$ due to the protonation of the $-\mathrm{NH}_{2}$ group. The NPK release of the freeze-dried hydrogels showed higher release percentage as more pores in the structure of the hydrogel were formed compared to the air-drying method.

\section{- REFERENCES}

[1] Khan, M.N., Mobin, M., Abbas, Z.K., and Alamri, S.A., 2018, "Fertilizers and their contaminants in soils, surface, and groundwater" in Encyclopedia of the Anthropocene, vol. 5, Eds. Dellasala, D.A., and Goldstein, M.I., Elsevier, Oxford, 225-240.

[2] Chen, J., Lü, S., Zhang, Z., Zhao, X., Li, X., Ning, P., and Liu, M., 2018, Environmetally friendly fertilizers: A review of materials used and their effects on the environment, Sci. Total Environ., 613-614, 829-839.

[3] Wu, L., and Liu, M., 2008, Preparation and properties of chitosan-coated NPK compound fertilizer with controlled-release and water-retention, Carbohydr. Polym., 72 (2), 240-247.
[4] Shaviv, A., and Mikkelsen, R.L., 1993, Controlled release fertilizers to increase efficiency of nutrient use and minimize environmental degradation: $A$ review, Nutr. Cycling Agroecosyst., 35, 1-12.

[5] Zhong, K., Lin, Z.T., Zheng, X.L., Jiang, G.B., Fang, Y.S., Mao, X.Y., and Liao, Z.W., 2013, Starch derivative-based superabsorbent with integration of water-retaining and controlled-release fertilizers, Carbohydr. Polym., 92 (2), 1367-1376.

[6] Rashidzadeh, A., Olad, A., Salari, D., and Reyhanitabar, A., 2014, On the preparation and swelling properties of hydrogel nanocomposite based on sodium-alginate-g-poly(acrylic acid-coacrylamide)/clinoptilolite and its application as slow release fertilizer, J. Polym. Res., 21, 344.

[7] Dehkordi, K.D., and Seyyedboveir, S., 2013, Evaluation of super AB A 200 superabsorbent on water use efficiency and yield response factor of SCKaroun701 corn under deficit irrigation, $A d v$. Environ. Biol., 7 (14), 4615-4622.

[8] Ahmed, E.M., 2015, Hydrogel: Preparation, characterization, and applications: A review, J. Adv. Res., 6 (2), 105-121.

[9] Sun, Y., Kaplan, J.A., Shieh, A., Sun, H.L., Croce, C.M., Grinstaff, M.W., and Parquette, J.R., 2016, Self-assembly of a 5-fluorouracil-dipeptide hydrogel, Chem. Commun., 52 (30), 5254-5257.

[10] Kim, S.H., Sun, Y., Kaplan, J.A., Grinstaff, M.W., and Parquette, J.R., 2015, Photo-crosslinking of a self-assembled coumarin-dipeptide hydrogel, New 


\section{J. Chem., 39 (5), 3225-3228.}

[11] Verhulsel, M., Vignes, M., Descroix, S., Malaquin, L., Vignjevic, D.M., and Viovy, J.L., 2014, A review of microfabrication and hydrogel engineering for microorgans on chips, Biomaterials, 35 (6), 1816-1832.

[12] Rajakumar, R., and Sankar, J., 2016, Hydrogel: Novel soil conditioner and safer delivery vehicle for fertilizers and agrochemicals - A review, Int. J. Appl. Pure Sci. Agric., 2 (9), 163-172.

[13] Ray, S.S., 2013, Environmentally Friendly Polymer Nanocomposites, Series in Composites Science and Engineering, Woodhead Publishing, Cambridge, United Kingdom.

[14] Nguyen, T.T.T., Hosh, C., Hwang, S.G., Tran L.D., and Park, J.S., 2013, Characteristics of curcuminloaded poly (lactic acid) nanofibers for wound healing, J. Mater. Sci., 48, 7125-7133.

[15] Kean, T., and Thanou, M., 2010, Biodegradation, biodistribution, and toxicity of chitosan, Adv. Drug Delivery Rev., 62 (1), 3-11.

[16] Ahmadi, F., Oveisi, Z., Samani, S.M., and Amoozgar, Z., 2015, Chitosan based hydrogels: Characteristic and pharmaceutical applications, Res. Pharm. Sci., 10 (1), 1-16.

[17] Jose, S., Fangueiro, J.F., Smitha, J., Cinu, T.A., Chacko, A.J., Premaletha K., and Souto, E.B., 2012, Cross-linked chitosan microspheres for oral delivery of insulin: Taguchi design and in vivo testing, Colloids Surf., B, 92, 175-179.

[18] Shelma, R., and Sharma, C.P., 2010, Acyl modified chitosan derivatives for oral delivery of insulin and curcumin, J. Mater. Sci. - Mater. Med., 21, 2133-2140.

[19] Jamelaa, S.R., and Jayakrishnan, A., 1995, Glutaraldehyde cross-linked chitosan microspheres as a long acting biodegradable drug delivery vechicle: Studies on the in vitro release of mitoxantrone and in vivo degradation of microspheres in rat muscle,
Biomaterials, 16 (10), 769-775.

[20] Ratti, C., 2012, "Freeze drying process design" in Handbook of Process Design, Eds. Ahmed, J., and Rahman, M.S., John Willey \& Sons, Hoboken, New Jersey, USA, 621-647.

[21] Adams, G.D., Cook, I., and Ward, K.R., 2015, The principles of freeze-drying, Methods Mol. Biol., 1257, 121-143.

[22] Shukla, S., 2011, Freeze drying process: A review, Int. J. Pharm. Sci. Res., 2 (12), 3061-3068.

[23] Wang, W., Chen, M., and Chen, G., 2012, Issues in freeze drying of aqueous solutions, Chin. J. Chem. Eng., 20 (3), 551-559.

[24] Day, J.G., and Stacey, G., 2007, Cryopreservation and Freeze-Drying Protocols, Springer Science and Business Media, Berlin.

[25] Anonymous, 2005, Water and waste water - Part 52: Test methods of nitrogen organic content by macro Kjedahl and titration, National Standardization Agency, Indonesian National Standard (SNI) 06-6989.52-2005.

[26] Jamnongkan, T., and Kaewpirom, S., 2010, Controlled release fertilizer based on chitosan hydrogel: Phosphorus release kinetics, Sci. J. UBU, 1, 43-50.

[27] Rasool, A., Ata, S., Islam, A., Rizwan, M., Azeem, M.K., Mehmood, A., Khan, R.U., Qureshi, A.R., and Mahmood, H.A., 2020, Kinetics and controlled release of lidocaine from novel carrageenan and alginate-based blend hydrogels, Int. J. Biol. Macromol., 145, 1-30.

[28] Akakuru, O.U., and Isiuku, B.O., 2017, Chitosan hydrogels and their glutaraldehyde-crosslinked counterparts as potential drug release and tissue engineering systems - Synthesis, characterization, swelling kinetics and mechanism, J. Phys. Chem. Biophys., 7 (3), 1-7. 